\title{
The Reactivation of Fetal Hemoglobin Synthesis during Anemia of Prematurity
}

\author{
HARRY BARD, CHRISTIAN LACHANCE, JOHN A. WIDNESS, AND CARMEN GAGNON \\ Department of Pediatrics, Perinatal Service and Research Center, Hôpital Sainte-Justine, \\ University of Montreal, Montreal, Quebec, Canada H3T IC5 [H.B., C.L., C.G./, and University \\ of Iowa Hospitals, Iowa City, Iowa 52242 [J.A.W.]
}

\section{ABSTRACT}

Increased fetal $\mathrm{Hb}(\mathrm{HbF})$ synthesis has been shown to occur during fetal hypoxemia and severe anemia. To determine whether increased HbF synthesis occurs during anemia of prematurity, the levels of HbF synthesis were correlated with the degree of anemia and plasma erythropoietin levels. Thirteen newborn infants born at $29.2 \pm 1.7$ wk of gestation were studied at a postconceptional age 36.0 \pm 1.1 wk. Hb levels ranged from 65 to $78 \mathrm{~g} / \mathrm{L}$. Blood samples were incubated in an amino acid mixture containing $\left[{ }^{3} \mathrm{H}\right]$ leucine and chromatographed allowing the separation and quantitation of the $\alpha, \beta$, and $\gamma\left({ }^{\mathrm{A}} \gamma^{\mathrm{T}},{ }^{\mathrm{G}} \gamma\right.$, and $\left.{ }^{\mathrm{A}} \gamma^{\mathrm{I}}\right)$ chains. Erythropoietin was determined by RIA. The mean HbF synthesis was $77.9 \pm 8.9 \%$ of total Hb synthesis (range: 61 to $91 \%$ ). Plasma erythropoietin concentrations were $21.4 \pm 6.4 \mathrm{mU} / \mathrm{mL}$. There was no correlation between the total $\mathrm{Hb}$ or $\mathrm{HbF}$ synthesis and the level of erythropoi-

In humans during the perinatal period, HbF is progressively replaced by $\mathrm{HbA}$. Studies of actively synthesized $\mathrm{Hb}$ demonstrate a gradual switchover from $\mathrm{HbF}$ to $\mathrm{HbA}$. This process follows a sigmoid curve, with the steep portion starting around $32 \mathrm{wk}$ of gestation $(1,2)$. The switchover is dependent on postconceptional age (3). However, it is of interest to note that during fetal development increased $\mathrm{HbF}$ production has been documented in humans with intrauterine growth retardation (4), especially as a result of placental insufficiency (5), and in the fetal lamb under experimental conditions of hypoxemia (6). In older patients, chronic lung disease (7) and anemia $(8,9)$ have also caused an increased production of $\mathrm{HbF}$. These findings suggest that the increase in the production of $\mathrm{HbF}$ could be the result of an erythropoietic response to hypoxemia.

Received November 8, 1993; accepted March 10, 1994.

Correspondence and reprints request: Harry Bard, M.D., Research Center, Hôpital Sainte-Justine, 3175 Chemin Côte Sainte-Catherine, Montreal, Quebec, Canada H3T 1 C5.

Supported by grants from the Medical Research Council of Canada (MA 11552) and National Institute of Health (PO1 HL46925).

${ }^{1}$ Presented in part at the SPR/ASP meeting, May 1993, Washington, DC. etin. There was, however, a significant inverse correlation between the $\mathrm{Hb}$ level and $\mathrm{HbF}$ synthesis $(p<0.01)$. Nine infants who had received transfusions during the first few days of life had a mean $\mathrm{HbF}$ that was $53.5 \pm 15.2 \%$ of total $\mathrm{Hb}$, whereas their HbF synthesis was $78.4 \pm 7.6 \%$. Four of the infants never received transfusions; the total circulating $\mathrm{HbF}$ and $\mathrm{HbF}$ synthesis in these infants were $87.7 \pm 7.7 \%$ and $76.8 \pm 12.7 \%$, respectively. This study shows that there can be a reactivation of $\mathrm{HbF}$ synthesis during severe anemia of prematurity. (Pediatr Res 36: 253-256, 1994)

HbF, fetal $\mathrm{Hb}$

Abbreviations

HbA, adult $\mathrm{Hb}$

TFA, trifluoroacetic acid

Epo, erythropoietin

Preterm newborn infants during their first few months of life normally undergo a decline in their $\mathrm{Hb}$ concentration that can reach in some cases a nadir of less than 80 $\mathrm{g} / \mathrm{L}$. This phenomenon is called anemia of prematurity (10). This anemia in the preterm infant occurs during a period of development that corresponds with the time of rapid switchover from $\mathrm{HbF}$ to $\mathrm{HbA}$ synthesis. Therefore, it was considered important to determine whether during this stage of ontogeny anemia could reactivate $\mathrm{HbF}$ synthesis. A study was thus planned to measure $\mathrm{HbF}$ and HbA synthesis as well as Epo levels in early preterm newborn infants during their anemia of prematurity and to correlate the findings with the degree of anemia.

\section{METHODS}

Thirteen infants born at or before $32 \mathrm{wk}$ of gestation without congenital anomalies were selected for this study. Gestational age was based on menstrual history and prenatal ultrasonography and was confirmed by clinical examination. Infants were included if they had a postnatal age $\geq 4 \mathrm{wk}$, had a venous $\mathrm{Hb}$ concentration $<$ $80 \mathrm{~g} / \mathrm{L}$, did not require supplemental oxygen, and had no 
cardiopulmonary disease. The blood used for this study was obtained from the sample withdrawn for cross matching after a decision was made by the attending neonatologist to give the infant a transfusion (the indication for transfusion during anemia of prematurity for asymptomatic infants at the time of the study was an $\mathrm{Hb}$ concentration $<80 \mathrm{~g} / \mathrm{L}$ ). Nine of these infants had received $8-16 \mathrm{~mL}$ of blood as volume replacement during their first few days of life to replace blood withdrawn for laboratory analysis as part of their intensive care monitoring. The interval between the last transfusion for volume replacement and this study was at least $26 \mathrm{~d}$ (range: 26-54 d).

The red cells obtained from the anemic infant were incubated for $6 \mathrm{~h}$ in an amino acid mixture containing $\left[{ }^{3} \mathrm{H}\right]$ leucine as previously described $(3)$. The cells were then washed and lysed, and the hemolysate was subjected to globin-chain separation and quantitation by a reverse-phase high-pressure liquid chromatograph equipped with an integrator according to the method described by Shelton et al. (11) This method uses a gradient between aqueous TFA and TFA in acetonitrile, and it gives excellent resolution of human globin chains. The equipment consisted of a Waters automated gradient controller, a Waters data system model QA-1, two Waters pumps model 510, and a Waters absorbance detector model 441 (Millipore Corporation, Waters Chromatography Division, Milford, MA). The chromatographic column (The Separations Group, Hesperia, CA) was a Vydac large-pore $(330 \mathrm{~A}) \mathrm{C} 4$ column $(4.6 \times 250 \mathrm{~mm})$. The absorbance was read at $214 \mathrm{~mm}$. The procedure of Shelton et al. (11) was followed with minor modifications. Mixture A contained $20 \%$ acetonitrile in water; in mixture $\mathrm{B}$, the concentration of acetonitrile was $70 \%$. The two solutions contained $0.1 \%$ TFA. The elution profile of newborn human globin chains was obtained with a gradient of 40 to $50 \%$ solvent $B$ in $70 \mathrm{~min}$ at a flow rate of 1 $\mathrm{mL} / \mathrm{min}$. This method provided a separation of the $\alpha$ and $\beta$ chains, as well as the three types of $\gamma$ chains $\left({ }^{\mathrm{A}} \gamma^{\mathrm{T}},{ }^{\mathrm{G}} \gamma\right.$, and $\left.{ }^{\mathrm{A}} \gamma^{\mathrm{I}}\right)$. Liquid scintillation counting was carried out on the separated globin fractions. The $\gamma$-globin chain synthesis was quantified by summing the areas under the ${ }^{\mathrm{G}} \gamma$, ${ }^{\mathrm{A}} \boldsymbol{\gamma}$, and ${ }^{\mathrm{A}} \gamma^{\mathrm{T}}$ peaks. The relative amounts of the separated fractions were obtained by use of a computer program (Inplot 4.02, GraphPad Software Inc., San Diego, CA) that provided a profile of the incorporation of $\left[{ }^{3} \mathrm{H}\right]$ leucine into the globin chains as well as their proportions. The results concurred with those obtained by the cutout and weighing procedure. The percentage of $\mathrm{HbF}$ was calculated by the ratio $[\gamma /(\gamma+\beta)] \times 100$. The plasma concentration of Epo was measured by RIA (12).

The data were expressed as a mean and SD. The relationship between variables were sought using linear as well as stepwise regression analysis (13). A $p<0.05$ was considered statistically significant. Informed consent was obtained from all subjects, and this investigation was approved and authorized by the institutional human research committee.

\section{RESULTS}

Thirteen infants were included in the study. Their mean gestational age was $29.2 \pm 1.7 \mathrm{wk}$, and their mean birth weight was $1262.3 \pm 391 \mathrm{~g}$. At the time they were included in the study, they had a mean postconceptional age of $36.0 \pm 1.1 \mathrm{wk}$, a mean postnatal age of $6.9 \pm 1.6$ wk, and a mean weight at the time of the study of 1880.4 $\pm 453.6 \mathrm{~g}$. Their mean $\mathrm{Hb}$ concentration was $71 \pm 4 \mathrm{~g} / \mathrm{L}$ (range: $65-78 \mathrm{~g} / \mathrm{L}$ ).

An example of an HPLC separation of the globin chains of a preterm infant born at $26 \mathrm{wk}$ of gestation who did receive some blood as replacement volume within the first week of life during intensive care, sampled at a postconceptional age of $34.5 \mathrm{wk}$, is illustrated in Figure 1. The total $\mathrm{HbF}$ was $65.8 \%$, and $\mathrm{HbF}$ synthesis was $84 \%$. The total ${ }^{\mathrm{G}} \gamma$ and ${ }^{\mathrm{G}} \gamma$ synthesis were 70 and $69 \%$, respectively.

The mean $\mathrm{HbF}$ synthesis of all infants studied was 77.9 $\pm 8.9 \%$ (range: $61-91 \%$ ). The ${ }^{\mathrm{G}} \gamma$ to total $\gamma$ ratio was 70.4 $\pm 4.5 \%$, and the ${ }^{\mathrm{G}} \gamma$ to total $\gamma$ synthesis ratio was $69.2 \pm$ $2.7 \%$. This ratio was not affected by anemia or the level of $\mathrm{HbF}$ synthesis. Among the 13 infants studied, nine
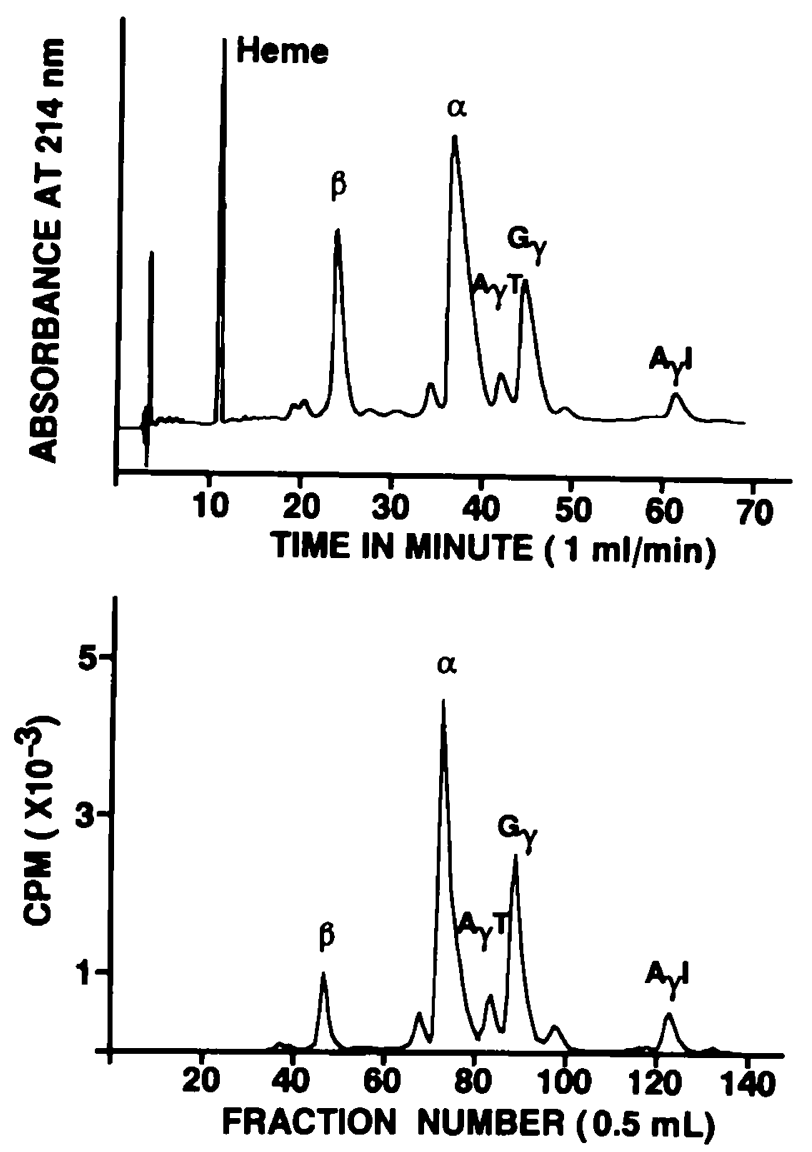

Figure 1. Chromatography of $\left[{ }^{3} \mathrm{H}\right]$-labeled globins separated by HPLC from a preterm infant born at $26 \mathrm{wk}$ of gestation sampled at a postconceptional age of $34.5 \mathrm{wk}$. Top, The absorbance at $214 \mathrm{~nm}$. Bottom, The $\mathrm{cpm}$ in each $0.5-\mathrm{mL}$ fraction. (The infant had received a packed red blood cell transfusion as replacement volume during the first week of life while requiring intensive care for respiratory distress syndrome.) The total $\mathrm{HbF}$ was $65.8 \%$, and the $\mathrm{HbF}$ synthesis was $84 \%$. The total ${ }^{\mathrm{G}} \gamma$ and ${ }^{\mathrm{G}} \gamma$ synthesis were 70 and $69 \%$, respectively. 
received at least one blood transfusion during their first few days of life during intensive care for respiratory distress syndrome. These nine infants had a mean gestational age of $28.9 \pm 1.6 \mathrm{wk}$ at birth, and at the time of the study their mean postconceptional age was $35.9 \pm 1.0$ wk. Their mean $\mathrm{HbF}$ was $53.5 \pm 15.2 \%$ of total $\mathrm{Hb}$, and their HbF synthesis was $78.4 \pm 7.6 \%$. Four of the infants studied never received transfusions. Their mean gestational age at birth was $30.5 \pm 1.3 \mathrm{wk}$, and their mean postconceptional age at the time of study was $36.3 \pm 1.3$ wk. The total circulating $\mathrm{HbF}$ and $\mathrm{HbF}$ synthesis in these infants were $87.7 \pm 7.7 \%$ and $76.8 \pm 12.7 \%$, respectively. The infants who did not receive transfusions had increased amounts of circulating $\mathrm{HbF}(p<0.001)$ but the same proportion of $\mathrm{HbF}$ synthesis as the infants who received transfusions.

The mean concentration of plasma Epo was $21.4 \pm 6.4$ $\mathrm{mU} / \mathrm{mL}$. There was no significant correlation between Epo concentration and $\mathrm{Hb}$ level $(r=0.35 ; p<0.4)$ or HbF synthesis $(r=0.23 ; p<0.5)$. Figure 2 demonstrates the relationship between $\mathrm{HbF}$ synthesis and postconceptional age (top) and $\mathrm{Hb}$ concentration (bottom), respectively. There was a significant inverse correlation of $\mathrm{HbF}$ synthesis with both these independent variables.
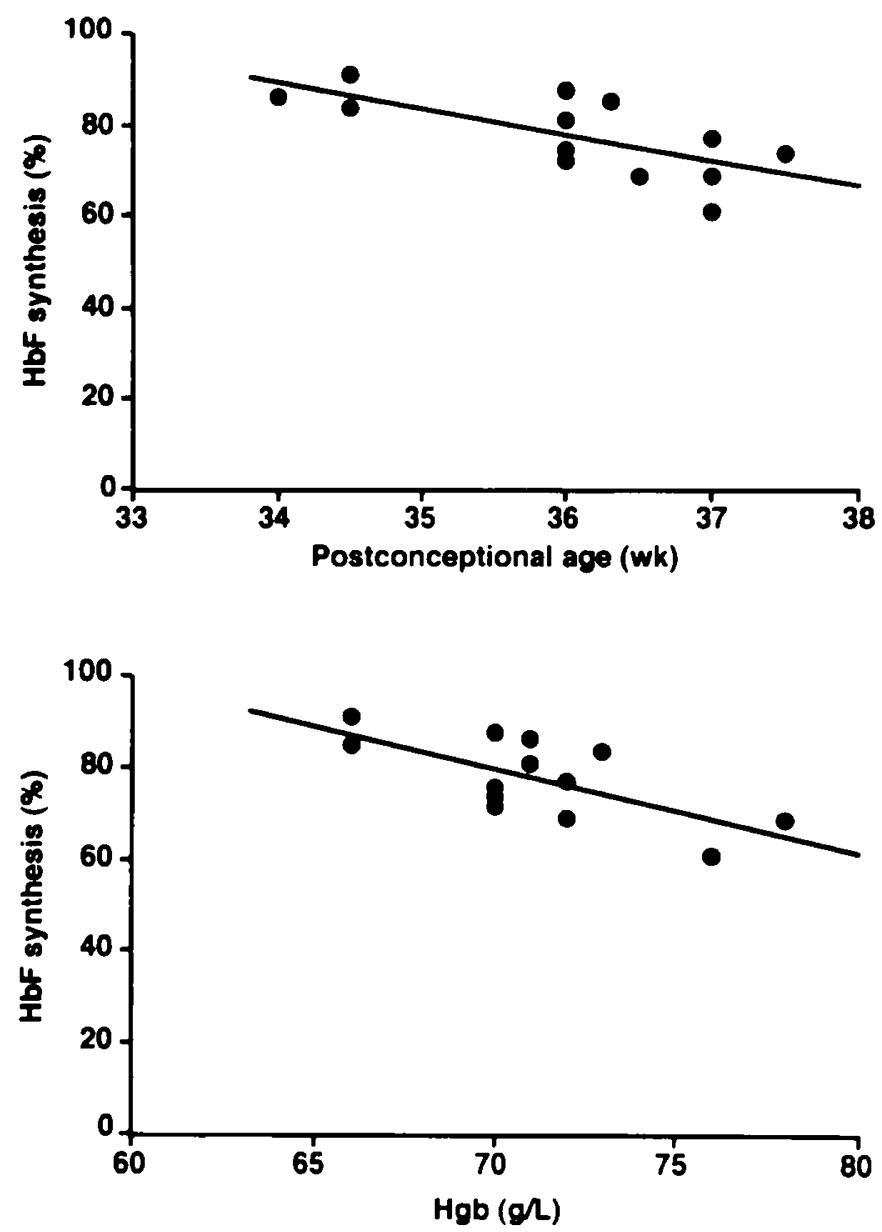

Figure 2. Top, Correlation between postconceptional age and $\mathrm{HbF}$ synthesis. $\mathrm{y}=-5.78 \mathrm{x}+285.5, r=0.70, p=0.008$. Bottom, Correlation between $\mathrm{Hb}$ concentration $(\mathrm{Hgb})$ and $\mathrm{HbF}$ synthesis. $\mathrm{y}=-1.84 \mathrm{x}$ $+209, r=0.69, p<0.01$
Because the switchover from $\mathrm{HbF}$ to $\mathrm{HbA}$ synthesis is primarily developmentally regulated, a stepwise regression was also carried out to take into account the effect of anemia and postconceptional age on the level of $\mathrm{HbF}$ synthesis (Table 1). These stepwise analyses showed a significant correlation between $\mathrm{HbF}$ synthesis and $\mathrm{Hb}$ concentration during anemia even when the relationship between $\mathrm{HbF}$ synthesis and postconceptional age was taken into account.

\section{DISCUSSION}

The reversed-phase HPLC procedure used in this study has been shown to be precise and very well suited for the quantitative determination of relative amounts of globin chains that make up the $\mathrm{Hb}$ of newborns (14). The mean ratio of ${ }^{G} \gamma$ to total $\gamma$ synthesis was similar to that documented by others in the fetus $(15,16)$.

Although there was an increased amount of total $\mathrm{HbA}$ in the circulation of the infants that received some adult red blood cell replacement during their first week of life compared with those who did not have a transfusion, the proportion of $\mathrm{HbF}$ synthesis to total $\mathrm{Hb}$ synthesis did not differ between the groups. Current evidence strongly shows that the control of $\mathrm{Hb}$ switching during ontogeny is under a developmental control that is inherent to the hematopoietic stem cells (17). However, the mechanisms of this developmental regulation is unknown. As a matter of fact, interdevelopmental stage hematopoietic cell transfer experiments in animals (18) as well as transfusions in utero (1) or after birth (3) in humans have had no effect on the timing of this $\mathrm{Hb}$ switchover. Consequently, all the infants included in the study could be considered part of the same group for the purpose of this investigation.

The production of Epo during anemia of prematurity was in the upper level of the range found in fetuses at a similar postconceptional age (19) but was lower than that in older anemic children with similar levels of $\mathrm{Hb}(20)$. Within the context of the relatively narrow $\mathrm{Hb}$ levels in this study, there was no relationship between Epo levels and $\mathrm{HbF}$ production. These findings are consistent with the well-known absence of Epo response to anemia of prematurity (21).

Erythropoiesis is under the control of a series of hematopoietic growth factors, some of which (IL-3, granulocyte-macrophage colony stimulating factor) have been shown in nonhuman primates to increase $\mathrm{HbF}$ production by their interaction with the erythroid progenitors as well

Table 1. Summary of stepwise regression *

\begin{tabular}{llccl}
\hline & & $r^{2}$ & $F$ & $p$ \\
\hline Step 1 & HbF vs PCA & 0.485 & 10.36 & 0.008 \\
Step 2 & HbF vs (Hgb + PCA) & 0.742 & 14.41 & 0.01 \\
& HbF vs Hgb $\dagger$ & 0.257 & 9.99 & 0.01 \\
\hline
\end{tabular}

* $\mathrm{Hgb}, \mathrm{Hb}$ concentration; PCA, postconceptional age.

$\dagger$ The effect of anemia on $\mathrm{HbF}$ synthesis after taking into account the contribution of PCA. 
as by their synergic interaction with Epo (22). In vitro (23) and in vivo (24) experimental observations have also shown that the maturation of the erythroid precursor cell is accompanied by a decreasing capacity to produce $\mathrm{HbF}$. During terminal maturation of erythrocyte precursors, there is a distinct transition from $\mathrm{HbF}$ to $\mathrm{HbA}$ production. The point in the maturation pathway at which the precursor cells become terminally committed to $\mathrm{Hb}$ synthesis determines the proportions of $\mathrm{HbF}$ and $\mathrm{HbA}$ in the progeny erythrocytes.

Thus, under normal conditions, the $\mathrm{Hb}$ synthesis reflects the proportion of $y$ to $\beta$ switch corresponding to the postconceptional age of human development. Conditions that promote the early commitment to $\mathrm{Hb}$ synthesis of the less mature precursor cell will result in increased $\mathrm{HbF}$ synthesis. If during severe anemia of prematurity these conditions, such as an increase in hematopoietic growth factors, exist, they would result in progeny that partially express an earlier fetal program of $\mathrm{Hb}$ type expression.

Indeed, our findings suggest a possible alteration in the normal expression of $\mathrm{Hb}$ during severe anemia of prematurity. The finding of increased synthesis of $\mathrm{HbF}$ in this study can possibly be explained by the concept of stress erythropoiesis in which the effect of an increased red cell demand alters the normal pattern of erythrocyte precursor proliferation and maturation. The result would be that red cells containing increased amounts of $\mathrm{HbF}$ appear in the circulation. We speculate that this mechanism could be triggered by a reduction of oxygen supply.

Acknowledgment. The authors thank Marc Dumont, M.P.S., for the statistical analysis.

\section{REFERENCES}

1. Bard H, Makowski EL, Meschia G, Battaglia FC 1970 The relative rates of synthesis of hemoglobins $A$ and $F$ in immature red cells of newborn infants. Pediatrics 45:766-772
2. Bard H 1975 The postnatal decline of hemoglobin $F$ synthesis in normal full-term infants. J Clin Invest 55:395-398

3. Bard H 1973 Postnatal fetal and adult hemoglobin synthesis in early preterm newborn infants. J Clin Invest 52:1789-1795

4. Humbert J, Abelson H, Hathaway WE, Battaglia FC 1969 Polycythemia in small for gestational age infants. J Pediatr 75:812-819

5. Bard H 1974 The effect of placental insufficiency on fetal and adult hemoglobin synthesis. Am J Obstet Gynecol 120:67-72

6. Bard H, Fouron JC. Prosmanne J, Gagnon J 1992 Effect of hypoxemia on fetal hemoglobin synthesis during late gestation. Pediatr Res 31:483-485

7. Bard H, Prosmanne J 1990 Elevated levels of fetal hemoglobin synthesis in infants with bronchopulmonary dysplasia. Pediatrics 86:193-196

8. Dover GJ, Boyer SH, Zinkham WH 1979 Production of erythrocytes that contain fetal hemoglobin in anemia. J Clin Invest 63:173-176

9. Papayannopoulou T, Vichinsky E, Stamatoyannopoulos G 1980 Fetal $\mathrm{Hb}$ production during acute erythroid expansion. Br J Haematol 44:535-546

10. Dalman PR 1981 Anemia of prematurity. Ann Rev Med 32:143-160

11. Shelton JB, Sherton JR, Shroeder WA 1984 High performance liquid chromatographic separation of globin chains on a large-pore C4 column. J Liq Chromatogr 7:1969-1977

12. Georgieff MK, Landon MB, Mills MM, Hedlund BF, Fassen AF, Schmidt LR, Ophove JJ, Widness JA 1990 Abnormal iron distribution in infants of diabetic mothers: spectrum and maternal antecedents. J Pediatr 117:455-461

13. Sokal RR, Rohlf FJ 1981 Biometry. WH Freeman and Company, New York pp $661-671$

14. Huisman THJ, Altay C 1981 The chemical heterogeneity of the fetal hemoglobin of black newborn babies and adults: a reevaluation. Blood 58:491-500

15. Alter BP 1979 The ${ }^{C} \gamma:{ }^{A} y$ composition of fetal hemoglobin in fetuses and newborns. Blood 54:1158-1163

16. Enoki Y, Ohga Y, Sakata S, Kohzuki H 1991 Postnatal transition of $\gamma$-globin gene expression in normal Japanese population. Br J Haematol 79:628-633

17. Weinberg RS, He L, Alter BP 1992 Erythropoiesis is distinct at each stage of ontogeny. Pediatr Res 31:170-175

18. Wood W, Bunch C, Kelly S, Gunn Y, Breckon G 1985 Control of haemoglobin switching by a developmental clock? Nature 313:320-323

19. Forestier F, Daffos F, Catherine N, Renard M, Andreux JP 1991 Developmental hematopoiesis in normal human fetal blood. Blood 77:2360-2363

20. Buchanan GR, Schwartz AD 1974 Impaired erythropoietin response in anemic premature infants. Blood 44:347-352

21. Brown MK, Garcia JF, Phibbs RH, Dallman PR 1984 Decreased response of plasma immunoreactive erythropoietin to "available oxygen" in anemia of prematurity. J Pediatr 105:793-798

22. McDonagh KT, Dover GJ, Donahue R, Nathan DG, Nienhuis AW 1989 Manipulation of $\mathrm{HbF}$ production with hematopoietic growth factors. In: Stamatoyannopoulos G, Nienhuis AW (eds) Hemoglobin Switching, Part B: Cellular and Molecular Mechanisms. Alan R Liss, New York, pp 307-315

23. Umemura T, Al-Khatti A, Papayannopoulou T, Stamatoyannopoulos G 1988 Fetal hemoglobin synthesis in vivo: direct evidence for control at the level of erythroid progenitors. Proc Natl Acad Sci USA 85:9278-9282

24. Stamatoyannopoulos G, Papayannopoulou T 1978 Fetal hemoglobin and the erythroid stem cell differentiation process. In: Stamatoyannopoulos G, Nienhuis AW (eds) Cellular and Molecular Regulation of Hemoglobin Switching. Grune \& Stratton, New York, pp 323-341 